Accepted author's manuscript. Published in final edited form as: Journal of Vascular and Interventional Radiology 2019; 30(5): 715-723. Publisher DOI: http://dx.doi.org/10.1016/j.jvir.2018.08.034

\title{
Clinical Impact of Chronic Venous Changes Induced by Central Lines in Children: A Cohort with Abnormal Venograms
}

Ralph Gnannt (MD) ${ }^{1,2}$, Racha Chamlati (MD) ${ }^{1}$, Nicolas Waespe (MD) ${ }^{3,4}$, Afsaneh Amirabadi (PhD) ${ }^{1}$, John Donnellan (MB) ${ }^{1}$, Joao Amaral (MD) ${ }^{1}$, Dimitri Parra (MD) ${ }^{1}$, Leonardo R. Brandão (MD, MSc) ${ }^{2}$, Bairbre Connolly (MB) $)^{1}$

${ }^{1}$ Image Guided Therapy, Diagnostic Imaging, The Hospital for Sick Children, University of Toronto, Toronto, Canada

${ }^{2}$ Pediatric Interventional Radiology, Department of Diagnostic Imaging, University Children’s Hospital Zurich, Zurich, Switzerland

${ }^{3}$ Department of Pediatrics, Division of Hematology/Oncology, The Hospital for Sick Children, University of Toronto, Toronto, Canada

${ }^{4}$ Swiss Childhood Cancer Registry, Institute of Social and Preventive Medicine, University of Bern, Bern, Switzerland

Type of Manuscript: $\quad$ Original research

Journal: $\quad$ JVIR

Key Words:

PICC, children, stenosis, collaterals, thrombus

Conflict of Interest:

Acknowledgements:

Corresponding Author: Helmut-Hartweg Funds.

Dr. Ralph Gnannt
The authors declare that they have no conflict of interest.

The author Ralph Gnannt was supported by EMDO-Foundation and

We thank the IGT team at The Hospital for Sick Children for assisting with recording and labeling of all the images that were used for our data analysis.

Image Guided Therapy

Diagnostic Imaging

The Hospital for Sick Children

University of Toronto

555 University Avenue

Toronto, ON, M5G 1X8

Canada

E-mail: ralph.gnannt@usz.ch 


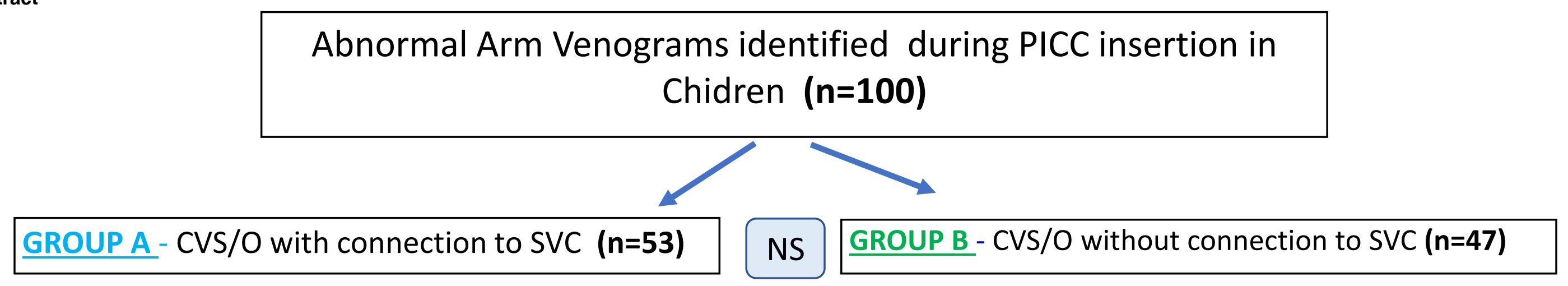

\section{GROUP A: History pre-venogram:}

- mean caliber of largest prior CVAD 3.6Fr

- mean \# of lumens 1.3

- polyurethane as a prior CVAD 25\%

Statistical

Differences

Group A v. B

$P<0.001$

$p<0.001$

$P<0.001$

$P=0.044$

\section{GROUP B: History pre-venogram:}

mean caliber of largest prior CVAD 4.5Fr

mean \# of lumens 1.7

polyurethane as a prior CVAD 70\%

- malpositioning of prior CVAD 30\%

\section{GROUP A: Post-Venogram Outcomes}

- success rate of PICC insertion 98\%

- Doppler US for new symptoms in $23 \%$

- Dx new thrombosis in 8\%

- median days of anticoagulation therapy 26.5 (4-1850)

\section{GROUP B: Post-Venogram Outcomes}

- success rate of PICC insertion 32\%

- Doppler US for new symptoms in 57\%

- Dx new thrombosis in 36\%

- median days of anticoagulation therapy 83 (2-1010)
Statistical

Differences Group A v. B

$p<0.001$

$\mathrm{P}=0.003$

$\mathrm{P}=0.002$

$\mathrm{P}=0.011$

\section{Time Line}




\begin{abstract}
Purpose:

To explore the hypothesis that central venous stenosis/obstruction $(\mathrm{CVS} / \mathrm{O})$ in children are influenced by prior central venous access devices (CVADs) and associated with future risk for thromboses.
\end{abstract}

\title{
Material and Methods:
}

A convenience sample of 100 patients with abnormal venography (stenosis, collaterals, occlusions) documented during Peripherally Inserted Central Catheter (PICC) placements were identified from consecutive PICC placements (Jan 2008-Nov 2012). The patients (41M, 59F, median age 2.7 years, median weight $11 \mathrm{~kg}$ ) were categorized based on venographic presence (Group A, $n=53$ ) or absence (Group B, $n=47$ ) of visible connection to the superior vena cava. Each patients' CVAD history, pre- and post-venography, was analyzed (until October 2016).

Results:

Pre-venogram, Group B were associated with a higher number of prior CVADs, larger diameter devices, greater incidence of malposition and more use of polyurethane catheters than Group A $(\mathrm{p}<0.001)$. An ipsilateral PICC was successfully placed in 98\% Group A, compared to $32 \%$ Group B $(\mathrm{p}<0.001)$. Post-venogram, significantly more Doppler ultrasounds (DUS) were performed, and thromboses diagnosed in Group B (57\% and 36\%) compared to Group A $(21 \%$ and $8 \%)(p<0.003 ; p=0.001)$ respectively.

\section{Conclusion:}

Previous catheter characteristics influenced the severity of venographic changes of CVS/O (Group B). Group B was associated with more subsequent symptomatic thromboses. This information may assist parents and referring physicians anticipate potential adverse sequelae from CVS/O on the child's venous health. 


\section{INTRODUCTION:}

Central vein stenosis or occlusion (CVS/O), a complication of central venous access devices (CVADs), may compromise future venous access, and result in venous stasis[1] [2] [3] [4]. CVS/O may occur from damage during CVAD insertion and from indwelling CVADs associated with turbulent flow, repetitive trauma, intimal hyperplasia, endothelial denudation and adherent thrombi [5] [6] [7]. CVS/O may be asymptomatic or symptomatic (e.g. edema of the ipsilateral extremity or the neck), and associated with thrombosis. The most prevalent risk factor for venous thromboembolism in children is a CVAD (80\%) [4] [8].

Venography during CVAD placement is not routine. In children, stenosis, occlusions, and venous collaterals are frequently observed on venograms performed during difficult peripherally inserted central venous catheter (PICC) placements [2]. It is unclear what prior vascular access events lead to the development of CVS/O, e.g. types of CVADs, infections, or thromboses. It is also unclear what the clinical implications are for the child's future vessel health when CVS/O are found (e.g. future risk of thrombosis, post-thrombotic syndrome, loss of central venous access) [9] [10] [11].

The purpose of this study was to analyze the preceding vascular access events (prevenogram) and subsequent clinical impact (post-venogram) of CVS/O diagnosed in children. The hypothesis was that central venous stenosis/obstruction (CVS/O) in children is influenced by prior central venous access devices (CVADs), and associated with future risk for thromboses.

MATERIAL AND METHODS

Study Design: 
This retrospective cohort study was conducted in a tertiary care-level pediatric teaching hospital. Institutional Research Ethics Board approval was obtained. The study cohort was identified from radiology reports on consecutive patients who had an abnormal contrast venogram during an image-guided (ultrasound, fluoroscopy) upper extremity PICC insertion in interventional radiology (IR), regardless of diagnosis, indication or number of prior CVADs (Figure 1). The convenience target sample size was 100 abnormal venograms. Inclusion criteria were patients undergoing an upper extremity PICC placement with abnormal venography showing deep venous stenosis or occlusion of the subclavian, brachiocephalic, or the superior vena cava (SVC), and/or opacification of venous collaterals. Patients were excluded if no venogram was performed, venogram was normal, images not stored or image quality too poor to assess vessel patency. Only abnormalities of the central venous system were included. Abnormalities of the superficial and deep veins of the arm (brachial, cephalic, basilic veins) were excluded (Fig. 1).

The search period started in January 2008, to ensure a sufficient sample size and to allow adequate follow-up for all patients. The target $(\mathrm{n}=100)$ was reached in November 2012, providing minimum follow-up of 4 years (study terminated 2016). The 100 patients were categorized into two groups by authors XX (radiologist 9 years experience) and YY, (medical student, co-author), with a review of 10 cases for consensus / audit purposes, by radiologist (ZZ, 24 years experience). Groupings were based on extent of the abnormalities seen on venography and divided into Group A and Group B, with the venographic changes more extensive in Group B:

Group A: Abnormal appearance (stenosis, wall irregularities or occlusion) of the central veins (subclavian, brachiocephalic or SVC), and visible venous collaterals, with an opacified connection to the SVC - through the native vein or a collateral (Fig. 2). 
Group B: Abnormal appearance (stenosis, wall irregularities or occlusion) of the central veins (subclavian, brachiocephalic or SVC), and visible collaterals, but without any opacified connection to the SVC (Fig. 3).

Results were organized and analyzed in two-time frames: pre-venogram and postvenogram. Each patient's CVAD history, pre- and post-venography, was examined, with follow up (October 2016). A subanalysis was performed to examine the effect of age ( $\leq 6$ and $>6$ months).

\section{Data Collection:}

Data was collected from the Electronic Patient Charts, Vascular Access Database, the IR Database (Esh-IGT, www.esh.ca; Ontario, Canada), a Hematology Departmental Database (Thrombosis), and PACS (GE, Milwaukee, USA). All feasible cross-referencing and confirmation techniques were employed between databases to ensure accuracy of the data.

To determine potential risk factors for developing $\mathrm{CVS} / \mathrm{O}$, the following was recorded:

Pre-venogram: (i) patient demographics at the time of the venogram, (ii) number, type, size and dwell times of all prior CVADs in the patient's history (including PICCs, central venous catheters, hemodialysis catheters, ports), number of venous Doppler ultrasounds (DUS) performed; number of thromboses diagnosed, and anticoagulation, (iii) most recent catheter in-situ prior to the venogram (called antecedent device) including the catheter material (silicone or polyurethane), cuffed or uncuffed, side employed (left or right), vein used (basilic, brachial, subclavian, cephalic, internal jugular), indication for catheter (chemotherapy, antibiotics, total parenteral nutrition (TPN), medication, and/or fluids), and complications (thromboses, infection, malposition). 
Post-venogram: success or failure of PICC placement during procedure with venogram, thromboses post-venogram (number of DUS examinations performed and thromboses diagnosed), anticoagulation and clinical sequelae from thrombosis (e.g. superior vena cava syndrome (SVCSyn), post thrombotic syndrome (PTS), chylothorax (CThx)). Prior cardiac surgery was recorded as a risk factor for developing above sequelae.

\section{Definitions and Practice:}

Central veins included SVC, brachiocephalic and subclavian vein. The deep veins included SVC, brachiocephalic, internal jugular, subclavian, and axillary. The superficial veins included the cephalic, basilic, and external jugular veins. Thromboses were diagnosed on venous DUS pre- and post-venogram and defined using recognized sonographic criteria [12] .A sonographically confirmed thrombus (occlusive or non-occlusive) was counted as one event; subsequent thrombus found in a different vein was counted as a second event. Venous DUS assessment was performed on site: a) in clinically indicated symptomatic children (e.g. extremity swelling, pain, leaking at the CVAD site, or catheter malfunction suggestive of venous occlusion); or b) for follow up of a known thrombosis. Routine DUS thrombosis surveillance screening was not performed. Catheter related blood stream infections (CRBSI) were laboratory proven. Catheter malpositions were based on radiographs.

Anticoagulation was defined as prophylactic (i.e. half of the treatment dose) or therapeutic (i.e. full treatment dose) based on recognized criteria using variety of medications across all age groups (footnote Table 2) [13]. Prophylactic anticoagulation was only administered after CVAD insertion in patients with a history of a previous thrombosis and continued until removal of the CVAD. Therapeutic anticoagulation was administered following a documented deep venous thrombus usually for three months, or longer if 
persistence of the thrombotic risk factor was demonstrated, as per international guidelines [13]. PTS was defined as per the modified Villalta score (Mild Moderate, Severe), a commonly used pediatric instrument for PTS detection [14], in the Thrombosis Clini[15]. Mild PTS corresponds to greater than $1 \mathrm{~cm}$ circumference differences with the contralateral arm and/or increased ipsilateral venous collaterals [14] [15].

Venography

A venogram, including shoulder and upper chest area, was performed during PICC placement at the discretion of the interventionalist, if difficulty was encountered advancing a guide wire or catheter centrally into the brachiocephalic vein and/or SVC. Contrast was handinjected from the initial access site (basilic, cephalic, brachial, axillary vein), through a dilator, or through the non-advanced PICC.

\section{Patient Population}

Of 3,862 PICCs placed in IR (2008-2012), 100 abnormal venograms were identified (Figure1). There were 41 boys and 59 girls. The mean patient age was 2.7 years and mean weight $11 \mathrm{~kg}$ (Table 1); The CVS/Os involved the right upper extremity in 94, and the left in six. Fifty-three venograms were categorized into Group A and 47 venograms into Group B; 49 patients were $\leq 6$ months, and $51>6$ months. There was no statistical difference in age, weight or gender between Group A and B ( $>>0.05)$.

\section{Statistical Analysis:}

SPSS version 23.0 for Windows (SPSS Inc., Chicago, IL) was used. Frequency distributions and cross-tabulations of variables of interest were obtained. The Shapiro-Wilk 
test was used to assess normal distribution. Results were expressed as mean $\pm \mathrm{SD}$ or median where appropriate. Student's t-test or Mann-Whitney U test was used for group comparisons for continuous variables. Chi-square or Fisher exact test was used to compare categorical variables. Differences were considered significant at $p<0.05$ (two-tailed); $p>0.05$ were not significant, NS. 


\section{RESULTS}

\section{PRE-VENOGRAM}

History of all CVADs Pre-venogram

The 100 patient cohort had received 437 prior CVADs, median of 1.73 CVADs per patient (range 1 - 7). The median cumulative dwell time of prior CVADs was 112 days (range 1-1429 days). The difference between Group A and B for number of CVADs and dwell time was not significant (Table 1). The median size of CVADs pre-venogram was 4.1 French (range $1.9-10$ ) and the number of lumens 1.47 (range 1 - 2). There was a significant difference between Group A and B in the patient's largest prior CVAD $(p<0.001)$ and the number of lumens $(\mathrm{p}<0.001)$ (Table 1). Group B was almost 3 times more likely to have had an ipsilateral polyurethane catheter compared to Group A (RR: 2.86, CI: $1.72-4.76$, $\mathrm{p}<0.001)$. The size of prior CVADs, number of lumens and dwell times were significantly greater in those $>6$ months than $\leq 6$ months $(\mathrm{p}=0.026, \mathrm{p}=0.005, \mathrm{p}=0.027$ respectively).

\section{The Antecedent Device Pre-venogram}

The antecedent catheter pre-venogram showed no significant difference between Group A and Group B in the following: use of cuffed or noncuffed catheters ( $p=0.13)$, vein accessed $(p=0.11)$, indication for device: TPN $(p=0.21)$, antibiotics $(p=0.85)$, medication $(\mathrm{p}=0.81)$, nor for device infection $(\mathrm{p}=0.42)$ or blockage $(\mathrm{p}=0.75)$. In Group B the antecedent catheter was more commonly of polyurethane material $(\mathrm{p}<0.001)$ and malpositioned $(\mathrm{p}=0.04)$ than Group A (Table 1). Both infection and malposition rates were higher than the institutional average for the relevant years $(2008-2012 ; 6 \%$ and $8 \%$ respectively). Diagnosis of Thromboses Pre-venogram

Seventy five DUS on the ipsilateral arm/central veins had been performed to evaluate new symptoms in 46/100 patients with 37 new thromboses diagnosed in 29/46 patients (Table 
2). More DUS were performed and thromboses diagnosed in Group B than Group A, but differences were NS ( $\mathrm{p}=0.073$ and 0.137 respectively).

Anticoagulation Pre-venogram

Six patients had been on prophylactic anticoagulation (2 in Group A, 4 in Group B), and 26 patients on therapeutic anticoagulation (12 in Group A, 14 in Group B) (Table 2). The median duration of prophylactic treatment in Group A was shorter than Group B, and median duration of therapeutic treatment longer in Group A than Group B, but the differences NS (Table 2).

\section{POST-VENOGRAM}

An ipsilateral PICC was successfully placed in 52/53 (98\%) patients in Group A, compared to $15 / 47(32 \%)$ in Group B $(\mathrm{p}<0.001)$.

Diagnoses of Thromboses Post-venogram

Seventy-one ipsilateral DUS were performed in 38/100 patients due to the onset of new symptoms, and 33 new thrombi diagnosed in 22/38 patients (See details in Table 2). Group B were significantly more likely to require a DUS ( $p=0.003 ; \leq 6$ months $p=001$; $>6$ months $\mathrm{p}=0.007)$ and have a new thrombosis $(\mathrm{p}=0.002 ; \leq 6 \mathrm{months} \mathrm{p}=0.045 ;>6$ months $p=0.001$ ) than Group A. Subset analysis of the 15 patients in Group B with a successful PICC showed 13 (89\%) had ipsilateral DUS performed for new symptoms and new thromboses diagnosed in 8/13 (62\%) patients (Fig. 4). The differences in ipsilateral thromboses between Group A and B with a successful PICC were highly significant (chi-square = 16.49; $\mathrm{p}<0.0001)$.

Anticoagulation Post-venogram 
Post-venogram 6/47 patients received prophylactic anticoagulation (4 in Group A; 2 Group B), and 29/47 patients required therapeutic anticoagulation (12 Group A; 17 Group B). The median duration of therapeutic anticoagulation was significantly longer in Group B $(p=0.011)$, the differences in prophylaxis duration was NS $(p=0.368)$.

\section{Clinical Sequelae Post-venogram}

The Hematology/Thrombosis Team monitored 38 patients for 51 new thromboses, including 12/38 monitored both pre and post venogram ( 1 was followed up elsewhere). Six of the 38 patients (15\%) patients were diagnosed with PTS (2 Group A; 4 Group B), 8/38 (21\%) with CThx (1 Group A; 7 Group B), and 2/38 (5\%) with SVCSy (1 Group A and 1 Group B). An underlying cardiac diagnosis was noted in 20/38 patients. PTS and CThx occurred more commonly in those with underlying cardiac disease (4/20 (20\%) and 7/20 (35\%)) respectively, compared to those without cardiac pathology (2/18 (11\%) and 1/18 $(5.6 \%)$ ) respectively (difference marginally significant $p=0.056$ ). SVCSy was similarly distributed between patients with and without an underlying cardiac disease (1/20 (5\%), 1/18 $(5.6 \%))$

\section{DISCUSSION}

Awareness of vessel health in children and preserving their venous access sites is a key responsibility of the pediatric interventional radiologist, especially in children with complex co-morbidities who face long-term or even lifelong vascular access needs [9-11]. The pediatric interventionalist may achieve this by simple measures e.g. ensuring a good indication for every inserted CVAD, reviewing prior imaging, placing the smallest size and 
fewest lumens to serve the child's needs, placing the CVAD tip centrally, and changing access sites only when necessary.

CVS/O is clinically important impacting the blood return to the heart. In severe cases, the entire upper venous system is compromised. This study explored a select group of children diagnosed with CVS/O, to evaluate factors associated with the development of CVS/O, as well as the sequelae of CVS/O. The cohort was associated with a higher incidence of previous infection and malposition than the institutional average. Patients in Group B were associated with larger diameter, more lumens, malpositions and use of polyurethane catheters in their prior CVADs than those in Group A. Successful PICC placement was significantly less frequent in Group B, with greater likelihood of subsequent symptoms (need for DUS, thromboses diagnosis and therapeutic anticoagulation).

The success rate for PICC placement in the ipsilateral arm with CVS/O (68\% overall, Group A and B combined) was lower than in an adult cohort by Park et al (86\%) [16]. A lower success rate was not unexpected as it included young children (mean age 2.7 years, mean weight $11 \mathrm{~kg}$ ) compared to adults. Stenosis in preexisting small veins would more likely prevent successful passage of a new PICC. Impact of these stenoses was seen in the numbers of patients who became symptomatic and required a DUS post PICC, indirectly indicating the critical nature of the stenosis with development of stasis/congestion symptoms in the presence of a new space occupying PICC.

The incidence of CVS/O after PICC or Port-a-cath insertion has been reported to be approximately 7\% [10]. In the same period of this study (2008-2012), 3,862 PICCs were placed in this institution. Identification of only 100 abnormal venograms is therefore low $(\sim 2.6 \%)$. Over half the cohort (54\%) had never undergone a prior DUS, i.e. they were asymptomatic, and CVS/O only became apparent during the difficult PICC insertion, suggesting CVS/O are frequently silent. Conversely not all symptomatic children were found 
to have associated thromboses on DUS. The cohort did not account for others who may have had CVS/O or thrombosis, but who did not undergo a subsequent PICC or venography, and remained undetected. The incidence of PICC associated peripheral thromboses detected by screening ultrasound in adults is much higher (72\%) [17]. The 100 children studied therefore represent the tip of an iceberg. The division into two groups based on the extent of venographic abnormalities, show clinically relevant differences in severity of CVS/O between both groups (requirement for US, success of ipsilateral PICCs, diagnoses of thromboses and clinical sequelae), with Group B more symptomatic than A, pre- and postvenogram.

The mechanism for forming CVS/O is not always known. Potential contributors are vessel wall damage at the time of insertion, indwelling catheters causing continuous endothelial damage, intimal hyperplasia, turbulent flow and thromboses [5] [18]. The preponderance on the right side reflected the institutional practice of using the right arm as first option for CVAD placement. The significant difference in catheter size and number of lumens between Group A and B potentially contributed to CVS/O. The relative size of vein to catheter is important, as the vein diameter is small in infants. Although no measurement of the diameters of the veins were taken, the vein sizes were likely similar as there was no significant difference in the ages and weights of patients in Group A or B. The mean age (2.7 years) and weight $(11 \mathrm{~kg})$ of the cohort are younger and smaller than the institutional average of patients undergoing a PICC ( 4.5 years; $18 \mathrm{~kg}$ ) suggesting that CVS/O might be more common in smaller children. Whether $\leq 6$ months and $>6$ months, Group B required more DUS and were diagnosed with more thromboses post venogram that Group A. However differences in variables such as dwell times, largest diameter and number of lumens of prior CVADs were more significant in those $>6$ months than $\leq 6$ months in Group B than A. 
Endothelial damage during catheter insertion may contribute to CVS/O. Inserting a double lumen PICC over a single wire results in an eccentric wire, and the vessel wall prone to damage from the blunt tip of the catheter. In this cohort, $43 \%$ double lumen CVADs (188/437) had been placed, whereas the institutional average in the same timeframe was $21 \%$ (819/3862). Vein injury also may occur from the catheter lying in contact with the vessel wall. Arm movement, breathing, and cardiac cycles causes catheter movement with friction on the endothelium [19]. Even short-term catheters can be associated with focal intimal injury and thrombus formation [18]. Significantly more polyurethane catheters were used in Group B compared to Group A, suggesting catheter material is important [20]. Although polyurethane softens at body temperature, polyurethane is a stiffer material than silicone. Surface irregularities on polyurethane devices make them more susceptible to thrombus adhesion $[21,22]$.

The present study has several limitations. A convenience sample was a chosen as a representative subgroup, but actual incidences may vary if a large prospective study was undertaken. The search terms may have overlooked or missed some cases. This study was not designed to determine causation for CVS/O. Differently designed prospective studies would be required to determine causality and validate findings of this study. A strength of the paper was the creation of a select cohort of patients with documented abnormal venography. Division into two groups was based on venographic patterns, which is prone to assignment error and inherent variability in venographic technique. Venographic image quality varied depending on the contrast volume injected which was usually small, and use of fluoroscopy or DSA. More precise characterization of the venographic abnormalities seen on venogram (e.g. assigning percentage stenosis, enumerating collaterals) would be inaccurate, due to such technical inconsistencies. Classification was based on an opacified venous connection to the SVC regardless whether it was a collateral or native vein. Park et al classified CVS/O and 
collaterals into three groups depending on distribution and degree of venous collaterals identified on venogram [16]. The rationale behind the classification used here was that symptoms (congestion, swelling, pain) are less likely if there is any route for adequate venous drainage of the limb (i.e. connection to SVC, Group A). The duration of CVS/O changes (acute or long standing) could not be determined. Prior catheter insertions were assumed not to be difficult (as no venogram had been performed). No measurement of vein sizes was available, so correlation with PICC French size was not done. No clinical comparisons were made between both groups in Hematology/Thrombosis follow-up clinics. Prophylactic anticoagulation may have been under-reported.

The findings indicate previous catheter characteristics (material, size, number of lumens, malposition) influence the severity of CVS/O. Detection of CVS/O on venography is associated with subsequent symptoms, with or without thromboses requiring anticoagulation. Many CVS/Os remain undiagnosed. It is debatable if a PICC should be placed ipsilaterally to CVS/O if there is no visible venous SVC connection, as thromboses are significantly more likely to occur. Adverse outcomes of PTS, SVCSy and CThx are more likely to occur in those with concomitant cardiac pathology (marginally significant). It behooves the interventionalist to review available images while planning a PICC. This study provides important information for the pediatric interventionalist to share with parents and referring physicians, to anticipate potential adverse sequelae on the child's future venous health. 


\section{REFERENCES}

1. Ters El M, Schears GJ, Taler SJ, et al (2012) Association between prior peripherally inserted central catheters and lack of functioning arteriovenous fistulas: a case-control study in hemodialysis patients. Am J Kidney Dis 60:601-608. doi: 10.1053/j.ajkd.2012.05.007

2. Yang RY, Moineddin R, Filipescu D, et al (2012) Increased complexity and complications associated with multiple peripherally inserted central catheter insertions in children: the tip of the iceberg. J Vasc Interv Radiol 23:351-357. doi: 10.1016/j.jvir.2011.11.024

3. Shin HS, Towbin AJ, Zhang B, et al (2017) Venous thrombosis and stenosis after peripherally inserted central catheter placement in children. Pediatr Radiol 27:556. doi: $10.1007 / \mathrm{s} 00247-017-3915-9$

4. Jaffray J, Bauman M, Massicotte P (2017) The Impact of Central Venous Catheters on Pediatric Venous Thromboembolism. Front Pediatr 5:5. doi: 10.3389/fped.2017.00005

5. Agarwal AK, Patel BM, Haddad NJ (2007) Central vein stenosis: a nephrologist's perspective. Semin Dial 20:53-62. doi: 10.1111/j.1525-139X.2007.00242.x

6. WESSLER S (1962) Thrombosis in the presence of vascular stasis. Am J Med 33:648666.

7. Stein PD, Sabbah HN (1974) Measured turbulence and its effect on thrombus formation. Circ Res 35:608-614.

8. Monagle P, Adams M, Mahoney M, et al (2000) Outcome of pediatric thromboembolic disease: a report from the Canadian Childhood Thrombophilia Registry. Pediatr Res 47:763-766.

9. Moureau NL, Trick N, Nifong T, et al (2012) Vessel health and preservation (Part 1): a new evidence-based approach to vascular access selection and management. The Journal of Vascular Access 13:351-356. doi: 10.5301/jva.5000042

10. Hallam C, Weston V, Denton A, et al (2016) Development of the UK Vessel Health and Preservation (VHP) framework: a multi-organisational collaborative. J Infect Prev 17:65-72. doi: 10.1177/1757177415624752

11. R Ventura - Liverpool: Aintree University Hospital NHS Foundation ..., 2016 (3AD) Implementing a Vessel Health \& Preservation Programme.

12. Prandoni P, Polistena P, Bernardi E, et al (1997) Upper-extremity deep vein thrombosis. Risk factors, diagnosis, and complications. Arch Intern Med 157:57-62.

13. Monagle $\mathrm{P}$, Chan AKC, Goldenberg NA, et al (2012) Antithrombotic therapy in neonates and children: Antithrombotic Therapy and Prevention of Thrombosis, 9th ed: American College of Chest Physicians Evidence-Based Clinical Practice Guidelines. Chest 141:e737S-e801S. doi: 10.1378/chest.11-2308 
14. Kuhle S, Koloshuk B, Marzinotto V, et al (2003) A cross-sectional study evaluating post-thrombotic syndrome in children. Thromb Res 111:227-233. doi: 10.1016/j.thromres.2003.09.008

15. Avila ML, Brandão LR, Williams S, et al (2016) Pediatric post-thrombotic syndrome in children: Toward the development of a new diagnostic and evaluative measurement tool. Thromb Res 144:184-191. doi: 10.1016/j.thromres.2016.06.035

16. Park KB, Choo SW, Do YS, et al (2008) Peripherally inserted central catheter placement in patients with unsuspected central venous obstruction. JVIR 19:552-556. doi: 10.1016/j.jvir.2007.10.010

17. Itkin M, Mondshein JI, Stavropoulos SW, et al (2014) Peripherally inserted central catheter thrombosis--reverse tapered versus nontapered catheters: a randomized controlled study. J Vasc Interv Radiol 25:85-91.e1. doi: 10.1016/j.jvir.2013.10.009

18. Forauer AR, Theoharis C (2003) Histologic changes in the human vein wall adjacent to indwelling central venous catheters. JVIR 14:1163-1168.

19. Connolly B, Amaral J, Walsh S, et al (2006) Influence of arm movement on central tip location of peripherally inserted central catheters (PICCs). Pediatr Radiol 36:845-850. doi: 10.1007/s00247-006-0172-8

20. Gnannt R, Waespe N, Temple M, et al (2018) Increased risk of symptomatic upperextremity venous thrombosis with multiple peripherally inserted central catheter insertions in pediatric patients. Pediatr Radiol 48:1013-1020. doi: 10.1007/s00247018-4096-x

21. Thomsen HK, Kjeldsen K, Hansen JF (1977) Thrombogenic properties of arterial catheters: a scanning electron microscopic examination of the surface structure. Cathet Cardiovasc Diagn 3:351-358.

22. Bourassa MG, Cantin M, Sandborn EB, Pederson E (1976) Scanning electron microscopy of surface irregularities and thrombogenesis of polyurethane and polyethylene coronary catheters. Circulation 53:992-996. 


\section{FIGURES}

\section{Figure 1:}

Flow Chart of the patient cohort.

\section{Figure 2:}

Example of venograms categorized as narrowing by the interventionalists (Group A). (a) 7year-old boy with two previous PICCs in the right arm. Vascular access was performed through the basilic vein. The venogram shows an abnormal appearance of the axillary/subclavian vein (arrow) but with a clear connection to the SVC (star). The PICC was placed without further issues on the ipsilateral arm. (b) 5-year-old girl with one previous PICC in the right arm. Oblique view of DSA (Digital Subtraction Angiography) from a brachial access shows two large draining veins however there is still a connection to the SVC. PICC was placed through the lower branch. 0.014" wire perforated this branch without further complications.

\section{Figure 3:}

Examples of venograms categorized as occlusions by the interventionalists (Group B). (a) 2year-old boy with two previous PICCs and a temporary right jugular catheter. Vascular access was performed through the brachial vein. The venogram shows complete occlusion of the axillary/subclavian vein. Note: sternal wire from prior cardiac surgery. After several attempts to advance the wire into the SVC, the right arm was abandoned and the PICC placed in the left arm. (b) 3-year-old girl with one previous right arm PICC. Access was made through the basilic vein, venogram showed complete occlusion of the subclavian vein with large collaterals descending the right lateral chest wall. 


\section{Figure 4:}

Venogram from a right arm vein in an 8-year-old female with prior PICC placed in the right arm. The native axillary vein is opacified but with complete occlusion of the subclavian vein (star). Opacification of the SVC (arrow) through collaterals is seen. Ultimately, a PICC was successfully placed through the occluded subclavian vein. Patient had an ultrasound due to severe swelling of the right arm at Day 2 and at Day 5 post-PICC insertion, a thrombus was seen in the right axillary vein. 
Click here to download high resolution image

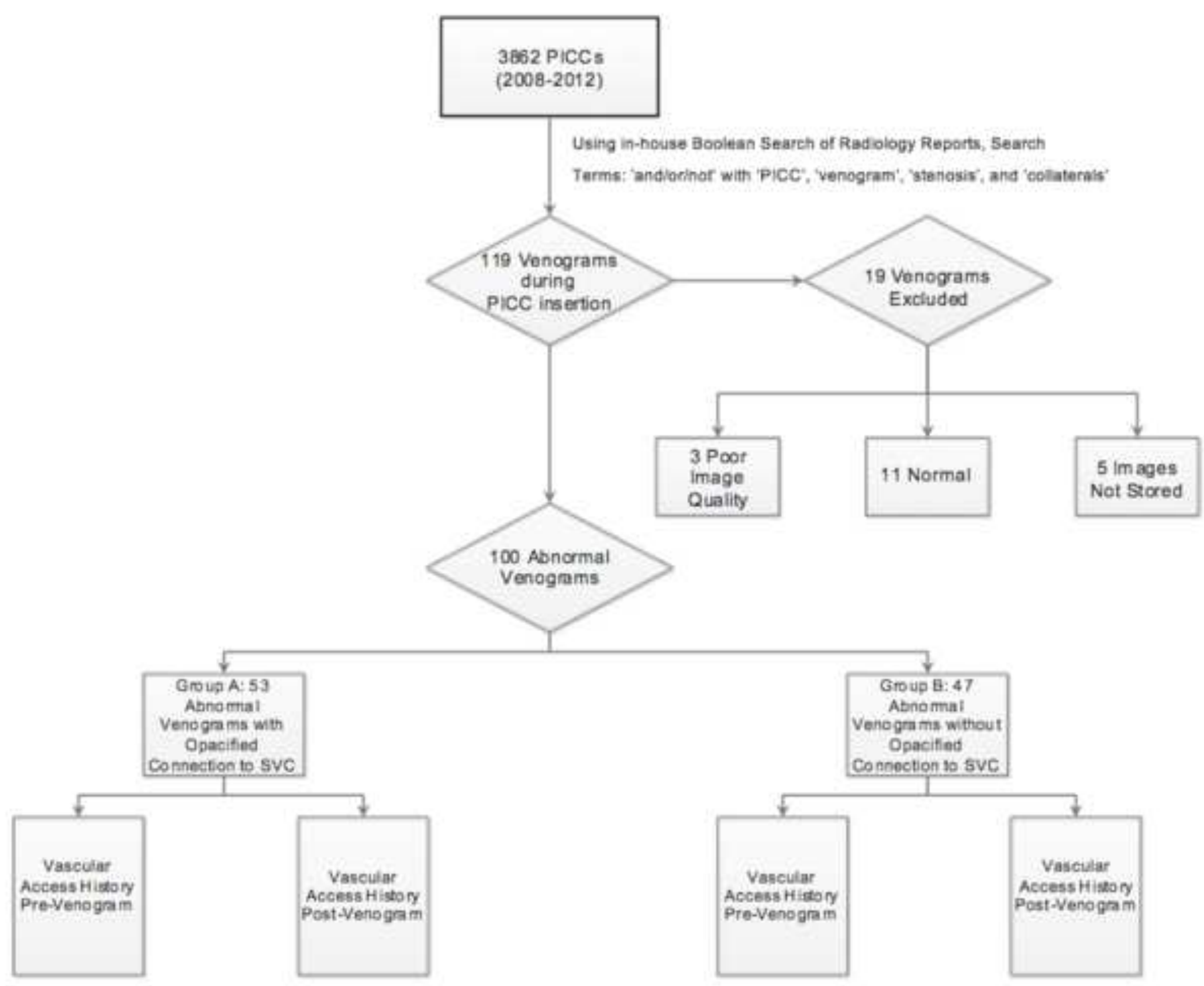




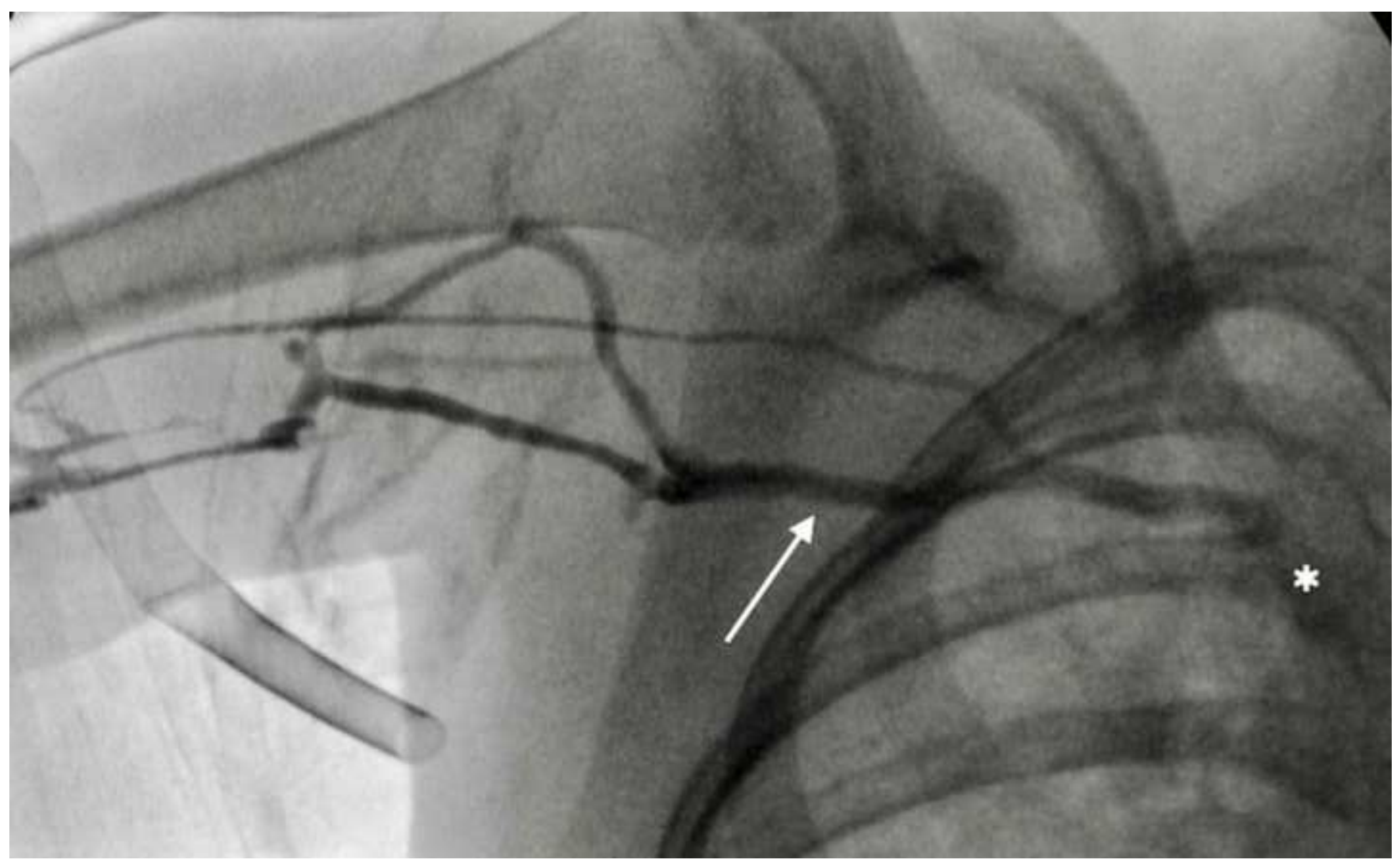




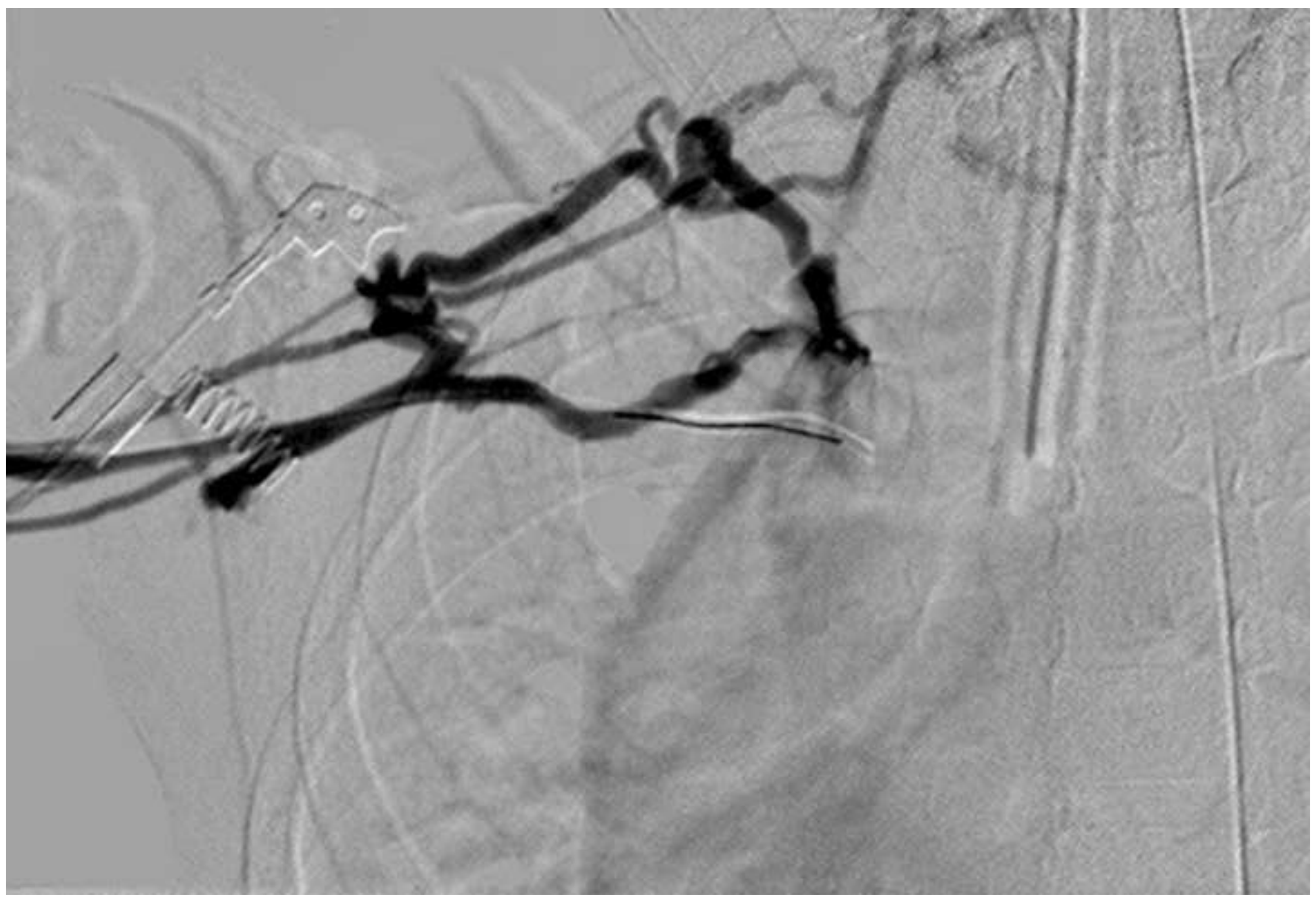


Figure $3 \mathbf{a}$
Click here to download high resolution image

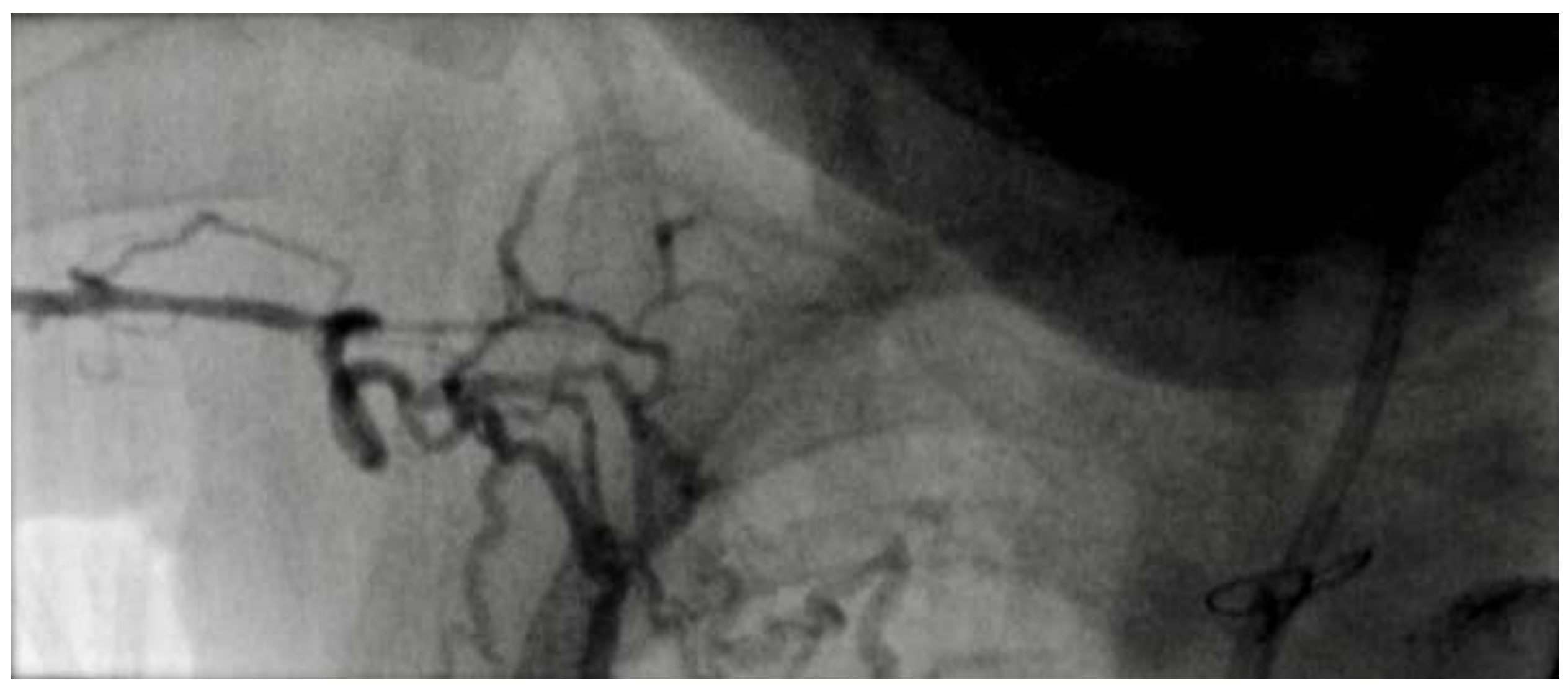


Figure $3 b$
Click here to download high resolution image

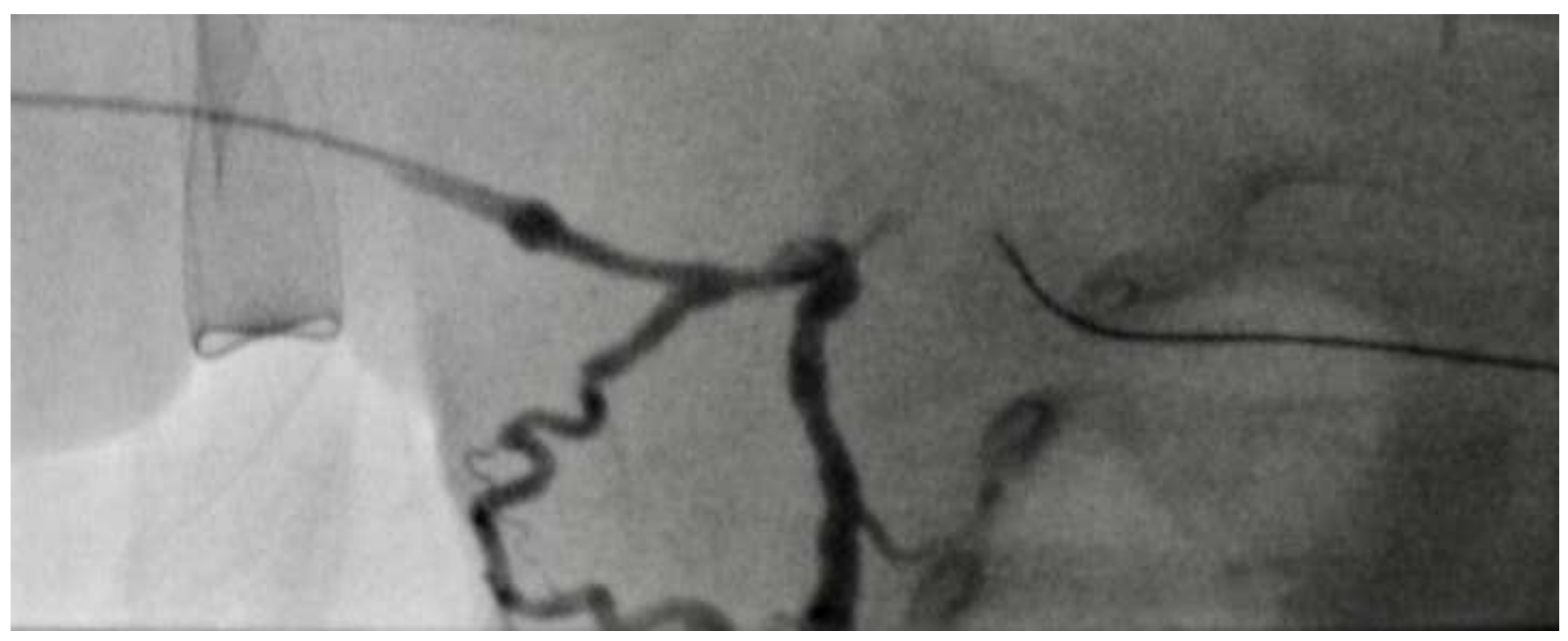


Figure $4 a$
Click here to download high resolution image

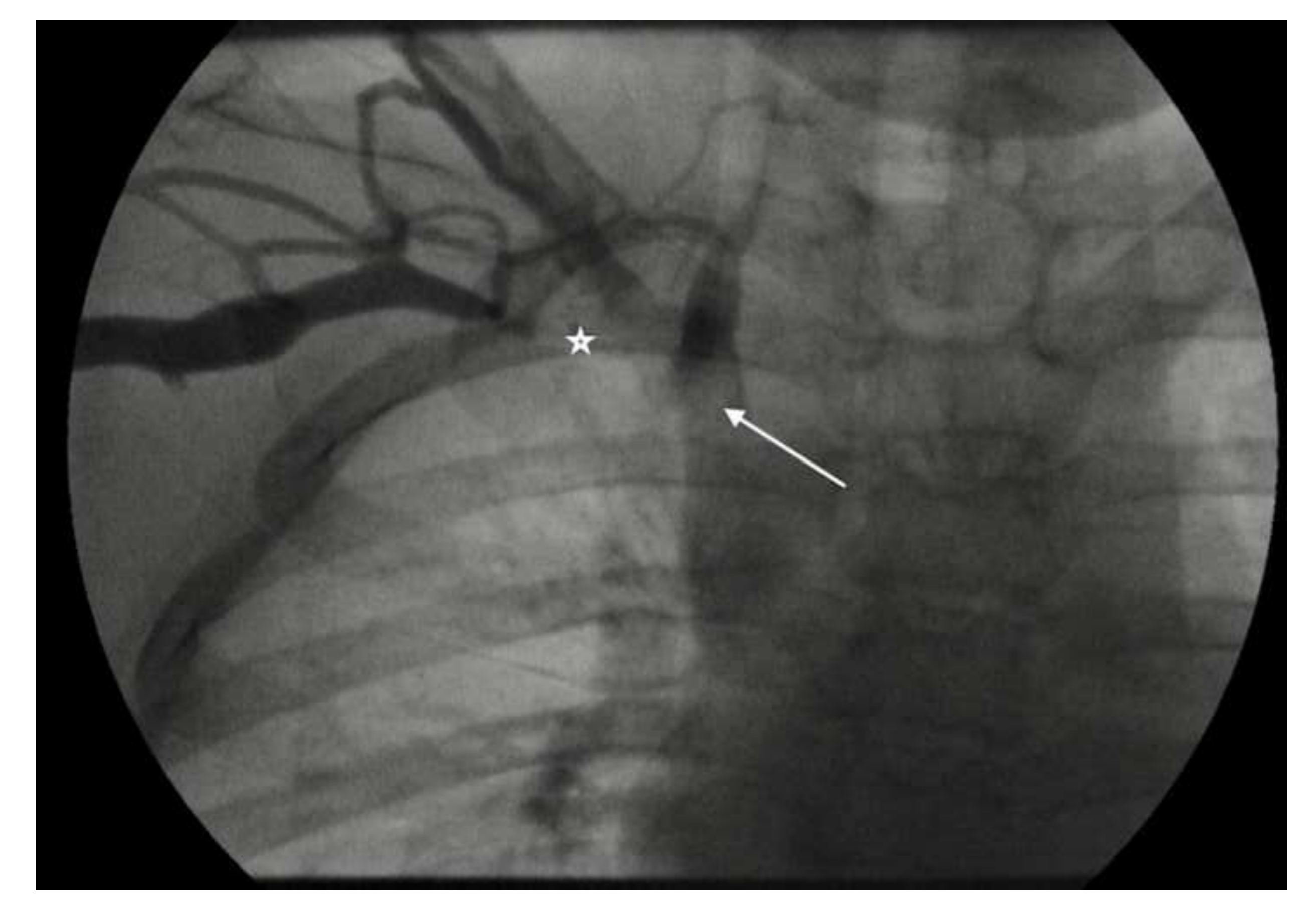

Figure $4 a$
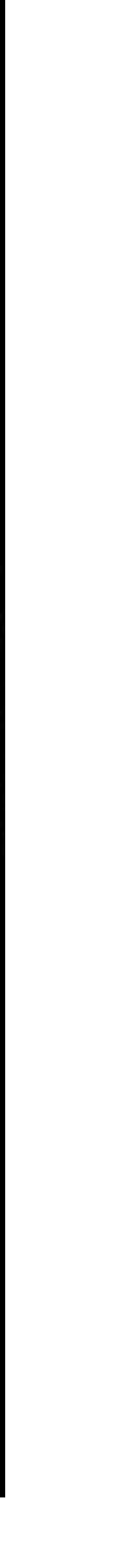
Click here to download high resolution image

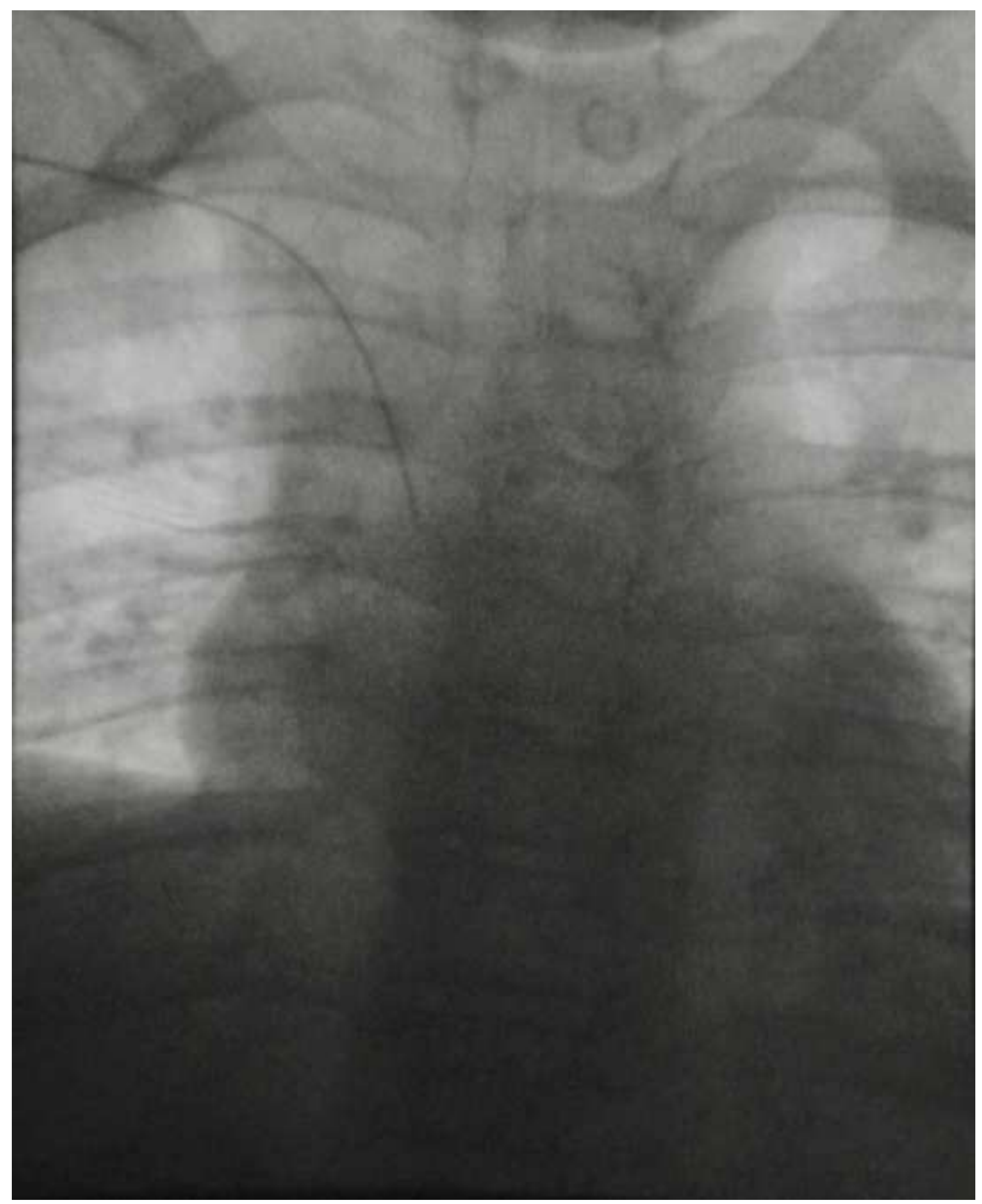


TABLES

Table 1. Clinical and Line Characteristics Pre-venogram

\begin{tabular}{|c|c|c|c|}
\hline All Lines & Group A $(n=53)$ & Group B $(n=47)$ & p Value \\
\hline Age in years: Mean (median, range) & $2.9(0.5 ; 0,04-17.3)$ & $2.6(0.5 ; 0,05-17.9)$ & 0.73 \\
\hline Weight in kg: Mean (median, range) & $11.9(4.45 ; 0.68-69.3)$ & $10.3(4.75 ; 0-66)$ & 0.71 \\
\hline Gender Male / Female & $21 / 32$ & $20 / 27$ & 0.97 \\
\hline Mean \# of devices before venogram & 1.8 & 1.7 & 0.82 \\
\hline $\begin{array}{l}\text { Mean French size of largest line } \\
\text { before venogram }\end{array}$ & 3.6 & 4.5 & $\mathrm{p}<0.001$ \\
\hline $\begin{array}{l}\text { Mean \# of lumens of lines placed } \\
\text { before venogram }\end{array}$ & 1.3 & 1.7 & $\mathrm{p}<0.001$ \\
\hline Mean dwell time, days & 111.3 & 112.6 & 0.113 \\
\hline \multicolumn{4}{|c|}{ Details of Antecedent Line Pre-venogram } \\
\hline Material Silicone / Polyurethane & $40 / 13$ & $14 / 33$ & $\mathrm{p}<0.001$ \\
\hline $\begin{array}{l}\text { Vein used for CVAD prior to } \\
\text { venogram IJV/SV/ } \mathrm{DV}^{*}\end{array}$ & $7 / 34 / 12$ & $8 / 18 / 21$ & 0.11 \\
\hline Line cuffed & 43 & 32 & 0.13 \\
\hline $\begin{array}{l}\text { Usage of line prior to venogram } \\
\qquad \text { TPN } \\
- \text { Antibiotics } \\
-\quad \text { Medication }\end{array}$ & $\begin{array}{l}21 \\
19 \\
13\end{array}$ & $\begin{array}{l}13 \\
16 \\
18\end{array}$ & $\begin{array}{l}0.21 \\
0.85 \\
0.81\end{array}$ \\
\hline Infection & 11 & 13 & 0.42 \\
\hline Malposition** & 7 & 14 & 0.04 \\
\hline Blockage & 6 & 4 & 0.75 \\
\hline
\end{tabular}

Legends:

*IJV=internal jugular vein, $\mathrm{SV}=$ superficial vein, $\mathrm{DV}=$ deep vein

** Malposition: Common malpositions include: a) central tip flipping into the contralateral brachiocephalic vein or jugular vein; b) tip ascending high with growth, into the SVC or inominate, c) descending low into the right atrium, 
Table 2. Comparison of Frequency of Ultrasounds, Thromboses, and Anticoagulation

\begin{tabular}{|c|c|c|c|c|}
\hline VARIABLE & $\begin{array}{l}\text { GROUPA } \\
(n=53) \\
\text { Group B } \\
(n=47)\end{array}$ & $\begin{array}{l}\text { PRE- } \\
\text { VENOGRAM }\end{array}$ & $\begin{array}{l}\text { POST- } \\
\text { VENOGRAM }\end{array}$ & $\begin{array}{l}\text { p-Value comparing } \\
\text { Pre- to Post- } \\
\text { Venogram }\end{array}$ \\
\hline \multirow{3}{*}{$\begin{array}{l}\text { \# DUS for new } \\
\text { symptoms } \\
\text { [\# of patients] }\end{array}$} & Group A & 33 [22] & 21 [11] & 0.202 \\
\hline & Group B & 42 [24] & $50[27]$ & 0.243 \\
\hline & $\begin{array}{l}\mathrm{p} \text {-Value comparing } \\
\text { Group A to Group B }\end{array}$ & $\mathrm{P}=0.073$ & $\mathrm{P}=0.003$ & \\
\hline \multirow{3}{*}{$\begin{array}{l}\text { DUS binomial* } \\
(\text { Yes/No) }\end{array}$} & Group A & $22(42 \%)$ & $11(23 \%)$ & 0.002 \\
\hline & Group B & $24(51 \%)$ & $27(57 \%)$ & 0.250 \\
\hline & $\begin{array}{l}\text { p-Value comparing } \\
\text { Group A to Group B }\end{array}$ & $\mathrm{P}=0.422$ & $\mathrm{P}<0.0001$ & \\
\hline \multirow{3}{*}{$\begin{array}{l}\text { \# New } \\
\text { thromboses } \\
\text { diagnosed } \\
\text { [\# of patients] }\end{array}$} & Group A & $14[12]$ & $7[4]$ & 0.002 \\
\hline & Group B & $23[17]$ & $26[17]$ & 0.250 \\
\hline & $\begin{array}{l}\text { p-Value comparing } \\
\text { Group A to Group B }\end{array}$ & $\mathrm{P}=0.137$ & $\mathrm{P}=0.022$ & \\
\hline \multirow{3}{*}{$\begin{array}{l}\text { Thrombosis } \\
\text { binomial* } \\
\text { (Yes/No) }\end{array}$} & Group A & $12(23 \%)$ & $4(8 \%)$ & 0.202 \\
\hline & Group B & $17(36 \%)$ & $17(36 \%)$ & 0.389 \\
\hline & $\begin{array}{l}\text { p-Value comparing } \\
\text { Group A to Group B }\end{array}$ & $\mathrm{P}=0.185$ & $\mathrm{P}=0.001$ & \\
\hline \multirow{3}{*}{$\begin{array}{l}\text { Median (range) \# } \\
\text { of days of } \\
\text { Prophylactic }^{\mathrm{P}} \\
\text { Anticoagulation } \\
\text { [\# of patients ] }\end{array}$} & Group A & $16(8-24)[2]$ & $118(1-278)[4]$ & 0.225 \\
\hline & Group B & $32(3-65)[4]$ & $123(19-228)[2]$ & 0.715 \\
\hline & $\begin{array}{l}\mathrm{p} \text {-Value comparing } \\
\text { Group A to Group B }\end{array}$ & $\mathrm{P}=0.394$ & $\mathrm{P}=0.368$ & \\
\hline \multirow{3}{*}{$\begin{array}{l}\text { Median (range) \# } \\
\text { of days of } \\
\text { Therapeutic }^{\mathrm{T}} \\
\text { Anticoagulation } \\
\text { [\# of patients] }\end{array}$} & Group A & $75(2-322)[12]$ & $26.5(4-1850[12]$ & 0.460 \\
\hline & Group B & $20.5(3-538)[14]$ & $83(2-1010)[17]$ & 0.022 \\
\hline & $\begin{array}{l}\text { p-Value comparing } \\
\text { Group A to Group B }\end{array}$ & $\mathrm{P}=0.963$ & $\mathrm{P}=0.011$ & \\
\hline
\end{tabular}

\# number

DUS: Doppler ultrasound 
Binomial $($ Yes or NO) = all ultrasound / thromboses are counted as one per patient, irrespective of number per patient

${ }^{\mathrm{P}}$ Prophylactic anticoagulation agents - heparin or enoxaparin used.

${ }^{\mathrm{T}}$ Therapeutic anticoagulation agents - heparin , enoxaparin, tinzaparin or warfarin.Rarely argatroban,

$\mathrm{P}, \mathrm{T}$ Anticoagulants included agents used to inhibit thrombin formation such as heparinoids [e.g., unfractionated heparin [UFH/heparin], low molecular weight heparin [LMWH/enoxaparin/tinzaparin], oral vitamin K antagonist [warfarin], and direct thrombin inhibitors [argatroban]). In terms of dosing, anticoagulants were used in either therapeutic dose (i.e., full dose) or in prophylactic dose (i.e, corresponding to $50 \%$ of full dose) and titrated per kilogram body weight. No difference in agents used in children $\leq 6$ months or $>6$ months except Tinzaparin used in two children aged 4 and 7.5 years. Warfarin was used exclusively in children with cardiac surgical conduits/baffles to maintain patency with a mean age of 3.6 years (versus 1.5 to 1.7 for heparin and enoxaparin, respectively). Antiplatelet agents (aspirin) were used in seven patients post cardiac surgery or liver transplantation to maintain patency of vessels, not for clot therapy. 